\title{
Influência da direção de semeadura do milho nas variáveis reflectância e índice de vegetação verde normalizado
}

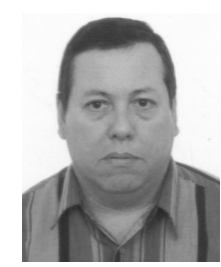

\author{
Eduardo G. de Souza', Gracielle A. Orlando², Miguel A. Uribe-Opazo³, \\ Edson A. da Silva ${ }^{4} \&$ Peter Scharf ${ }^{5}$
}

1 CCET/UNIOESTE. CP 711, CEP 85814-110, Cascavel, PR. Fone: (45) 220-3199. Email: godoy@unioeste.br (Foto)

2 UNIOESTE. E-mail: graorlando@hotmail.com

3 CCET/UNIOESTE. E-mail: mopazo@unioeste.br

4 CCET/UNIOESTE. E-mail: edsonsilva@unioeste.br

5 University of Missouri. 214 E Waters Hall, Columbia, MO 65211, USA. E-mail: scharfp@missouri

Protocolo 104 - 16/6/2003 - Aprovado em 6/2/2004

\begin{abstract}
Resumo: Com este trabalho, objetivou-se estudar a influência da direção de semeadura do milho (Zea Mays L.) na sua reflectância na banda $550 \mathrm{~nm}\left(\mathrm{r}_{550}\right)$ e no Índice de Vegetação Verde da Diferença Normalizado - IVVDN, visando fornecer informações necessárias à viabilização de um sistema de aplicação localizada de nitrogênio (N) em tempo real. O sistema de semeadura utilizado foi o direto, administrando-se os nutrientes de acordo com análise do solo e com uma taxa de $\mathrm{N}$ de $160 \mathrm{~kg} \mathrm{ha}^{-1}$. As linhas de semeadura foram localizadas na direção Norte-Sul e LesteOeste. Conclui-se que o milho semeado na direção Leste-Oeste apresentou valores para reflectância $r_{550}$ e índice de vegetação IVVDN menores e menos dependente da hora do dia que o milho semeado na direção Norte-Sul. O IVVDN mostrou-se mais apropriado para uso em sistemas de aplicação de fertilizantes a taxas variáveis em tempo real utilizando-se técnicas de sensoriamento remoto, por se mostrar menos sensível á direção de semeadura.
\end{abstract}

Palavras-chave: Zea mays L., IVVDN, sensoriamento remoto

\section{Influence of the row direction of corn on the reflectance and green normalized difference vegetation index}

\begin{abstract}
The objective of this work was to study the influence of the row direction of corn (Zea mays) on its spectral properties measured in the field, including the green normalized difference vegetation index (Green NDVI). Spectral properties of corn are known to be related to the nitrogen (N) status of the corn and may form the basis for real-time site-specific rates of $\mathrm{N}$ application. Row direction effects on spectral properties may be substantial before canopy closure. If so, it will be necessary to account for these effects in order to accurately predict the $\mathrm{N}$ need of corn from spectral measurements. Corn was planted directly, with no tillage, in North-South (NS) and East-West (EW) oriented rows. Nitrogen was applied as ammonium nitrate at a rate of $160 \mathrm{~kg} \mathrm{~N} \mathrm{ha}^{-1}$. Reflectance was measured with spectral radiometers placed $30 \mathrm{~cm}$ above individual plants. Reflectance and green NDVI were strongly dependent on time of day for corn in NS rows, and much less so for corn in EW rows. Reflectance and green NDVI were lower for corn in EW rows than corn in NS rows, but lack of replication makes it difficult to be certain that this was due to row direction. Green NDVI was less sensitive than reflectance to row direction and therefore may be more appropriate for use in a real-time variable-rate nitrogen application system.
\end{abstract}

Key words: Zea mays L., NDVI, remote sensing

\section{INTRODUÇÃO}

A técnica de Agricultura de Precisão (AP) consiste na aplicação localizada dos insumos agrícolas em função da necessidade específica local e se fundamenta na existência da variabilidade espacial dos fatores produtivos e, portanto, da própria quantidade produzida pela cultura (Balastreire et al., 1997). O desenvolvimento de tecnologias de aplicação de fertilizantes, a taxas variáveis, mostrou a necessidade de melhores métodos para se estimar as variabilidades dos fatores produtivos dentro dos talhões.

A medição da reflectância espectral é considerada promissora abordagem não invasiva para o sensoriamento instantâneo da deficiência de $\mathrm{N}$ em milho (Tumbo et al., 2000). O problema é que esta característica das plantas não é bem conhecida; ela possibilita a prática de aplicação de fertilizantes a taxas variáveis 
em tempo real e é influenciada por fatores como ângulo zenital, estádio vegetativo da planta e nebulosidade do dia, entre outros.

Segundo Wood et al. (1993) sistemas tecnificados de produção de milho requerem grande quantidade de $\mathrm{N}$, mas o excesso à necessidade nutricional da planta pode lixiviar e atingir o lençol freático, contribuindo para a eutrofização de lagos e fluxos de água. O aumento da concentração de nitratos no solo e na água tem exigido melhores técnicas de administração de nitrogênio, particularmente em áreas de produção de milho.

A clorofila é responsável pela coloração verde das folhas e tem mostrado alta correlação com a concentração de $\mathrm{N}$ das folhas, especialmente quando ele é deficiente deste nas folhas (Wolfe et al., 1988; Lohry, 1989; Schepers et al., 1992 citados por Blackmer et al., 1994). Thomas \& Oerther (1972) citados por Blackmer et al. (1994), mostraram que o nível de $\mathrm{N}$ nas folhas poderia ser rapidamente estimado pela quantidade de luz refletida no comprimento de onda de $550 \mathrm{~nm}$. Neste com primento de onda há menos absorção de energia que na região do azul (de 400 a $500 \mathrm{~nm}$ ) e vermelho (de 600 a $700 \mathrm{~nm}$ ).

Davis (1957) mostrou que a reflectância das plantas oscila com a elevação do sol. Seus valores variaram de $22 \%$ ao meio dia para aproximadamente $43 \%$ ao amanhecer e $48 \%$ no pôrdo-sol. Jackson et al. (1979) coordenaram um estudo sobre a dependência da reflectância espectral do trigo com a configuração da cultura (ou seja, a direção das linhas de semeadura) e a posição do sol. O trigo foi semeado em três disposições: em uma configuração ele foi semeado com um denso estande sem direção preferencial; nas outras duas configurações, o trigo foi semeado em linhas, espaçadas 30 $\mathrm{cm}$, uma na direção Norte-Sul (NS) e outra na direção LesteOeste (LO). Eles calcularam as reflectâncias para as bandas verde (500-600 nm), vermelho (600-700 nm) e infravermelho próximo (700-800 nm), entre outras. As medidas foram efetuadas quando as plantas estavam com aproximadamente $35 \mathrm{~cm}$ de altura. A influência da posição do sol na reflectância foi pequena para os solos nus e para o estande denso; no entanto, para as configurações em linha a reflectância mostrou-se altamente dependente do ângulo zenital e direção de semeadura. Os autores afirmaram, ainda, que a dependência da reflectância na banda visível ao ângulo zenital pode ser explicada com base na alta absorção das folhas verdes.

Em culturas em crescimento, as plantas absorvem a maior parte da radiação visível e sombreiam diferentes proporções do solo e de outras partes da planta, dependendo do ângulo zenital, da direção de semeadura e da altura da planta. Quando a direção de semeadura é a NS e se tem um baixo índice de área foliar, a maior parte do solo é sombreada pela manhã e a tarde, e menos sombreado ao meio dia solar; assim, a reflectância do dossel em qualquer banda atinge seu mínimo com o sol do meio dia. Para linhas de semeadura LO a fração do solo iluminada muda menos que para a direção NS e a reflectância apresenta menores mudanças. A banda do vermelho mostrou-se mais sensível que a banda verde, em relação ao ângulo zenital, já a banda do infravermelho, por sua alta transmitância através das folhas verdes, precisa de três a quatro vezes mais camadas de folhas para alcançar a mesma reflectância da luz visível. Para um alto ângulo zenital a luz penetra na cultura de tal forma que muitas folhas são atingidas, logo a reflectância é alta. Perto do meio dia solar a quantidade de folhas atingida diretamente é menor, ocasionando uma reflectância também menor no infravermelho. Verificou-se, ainda, que a direção de semeadura tem menor efeito na reflectância do infravermelho que na banda visível. O decréscimo da reflectância no infravermelho e o aumento na banda visível com o aumento da elevação solar indicam que índices que utilizem a relação da reflectância no infravermelho com a reflectância no verde ou no vermelho, deverão ser acentuadamente influenciados pelo ângulo zenital. Os autores concluíram que a configuração da cultura é um dos fatores mais determinantes na reflectância espectral do trigo e que os índices de vegetação a serem utilizados em estudos temporais deverão levar em consideração a elevação solar. Conse-qüentemente, a elevação solar ou o ângulo zenital deveriam ser especificados para o desenvolvimento de modelos apropriados de correção a serem utilizados no processamento de imagens orbitais e sub-orbitais adquiridas em diferentes datas.

Índices de Vegetação Espectrais (IVE) são úteis para minimizar variações devido a fatores estranhos e maximizar a sensividade à variável de interesse, neste caso a concentração de clorofila na folha do milho (Daughtry et al., 2000). Esses índices são determinados a partir da baixa reflectância nos comprimentos de onda visíveis e da alta reflectância nos comprimentos de onda infravermelho-próximo que são característicos da assinatura espectral de uma vegetação verde. O número relatado de IVEs é elevado e eles se agrupam em três categorias: (1) índices intrínsecos, (2) índices ajustados ao solo, e (3) índices ajustados à atmosfera. Daughtry et al. (2000) concluíram que alguns IVE, como a relação infravermelho próximo/vermelho, minimizaram as contribuições da reflectância de fundo, enquanto outros, como a relação entre o infravermelho próximo/verde responderam mais à concentração de clorofila da folha. Tumbo et al. (2000) encontraram uma forte correlação entre a relação de infravermelhos-próximo/verde e concentração de clorofila no estádio vegetativo V6 do milho, sob irradiância solar constante.

Objetivou-se, com este trabalho, estudar a influência da direção da semeadura do milho na reflectância na banda $550 \mathrm{~nm}$ e no índice verde de vegetação da diferença normalizada IVVDN. O conhecimento da magnitude de influência permitirá encontrar-se correções matemáticas que possibilitarão a conversão da reflectância na correta taxa necessária de N.

\section{MATERIAL E MÉTODOS}

Os dados foram levantados em laboratórios e campos experimentais da Universidade do Missouri, Columbia, MO, EUA. O milho foi instalado através da técnica de semeadura direta, administrando-se os nutrientes de acordo com a análise do solo e a uma taxa de $\mathrm{N}$ de $160 \mathrm{~kg} \mathrm{ha}^{-1}$. As coordenadas geográficas locais são: Latitude $38^{\circ} 54^{\prime} \mathrm{N}$ e Longitude $92^{\circ} 12^{\prime} \mathrm{W}$. As linhas de semeadura foram localizadas na direção NorteSul (NS) e Leste-Oeste (LO). O espaçamento entre plantas foi de $25 \mathrm{~cm}$ e entre linhas de $80 \mathrm{~cm}$, proporcionando uma população aproximada de 50.000 plantas ha-1. 
As medidas foram tomadas no período de 03/09/2002 a 05/09/2002, estando o milho no estádio vegetativo V6. Quatro radiômetros foram montados a $25 \mathrm{~cm}$ acima do ápice das plantas e posicionados verticalmente para baixo, oferecendo um campo de visão de $28^{\circ}$, o que representa $12,5 \mathrm{~cm}$ de diâmetro de visão. Devido a trajetória do sol no mês de setembro e o adequado espaçamento entre radiômetros, evitaram-se sombras sobre as plantas que estavam sendo monitoradas. Os radiômetros 1 e 5 foram posicionados sobre as linhas orientadas na direção $\mathrm{LO}$ e os radiômetros 2 e 3 sobre as linhas orientadas na direção NS. Os radiômetros foram calibrados um contra os outros visandose que diferenças nas reflectâncias calculadas não fossem originadas de diferenças entre os radiômetros mas, sim, devido as plantas sobre os seus campos de visão, tais como ao estado nutricional da planta e da geometria da radiação. Um radiômetro de campo de visão de $180^{\circ}$ (radiômetro 4) foi posicionado voltado verticalmente para cima, com vistas a se estimar a irradiação global. Os dados espectrais da cultura do milho foram obtidos em intervalos de dois segundos e, posteriormente, agrupados em intervalos de dois minutos com vistas a se reduzir o volume de dados. Nos três dias de medição $(03,04$ e 05/09/2002) levantaram-se dados das 8:00 às 18:00 h. A resposta espectral foi medida em duas bandas, cada uma com $10 \mathrm{~nm}$ de largura, centradas em $550 \mathrm{~nm}$ (verde) e $800 \mathrm{~nm}$ (infravermelho próximo). A reflectância do milho foi calculada por:

$$
\mathrm{r}_{\mathrm{i}}=\frac{\pi * \operatorname{Rad}(\mathrm{ji})}{\operatorname{Rad} 4(\mathrm{i})}
$$

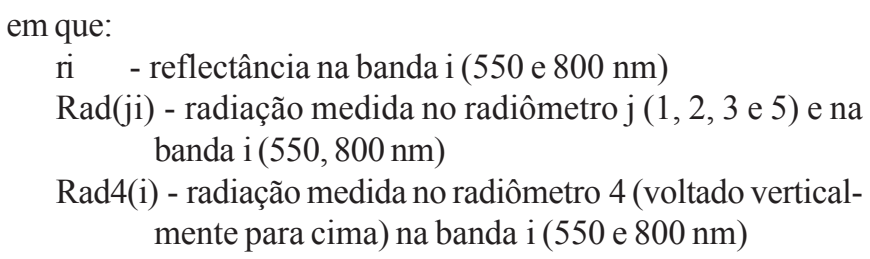

Com base nos resultados reportados por Daughtry et al. (2000), Tumbo et al. (2000) e Souza et al. (2002), selecionou-se o índice de vegetação:

$$
\operatorname{IVVDN}=\frac{r_{800}-r_{550}}{r_{800}+r_{550}}
$$

em que:

IVVDN - Índice verde de vegetação da diferença normalizada (Green Normalized Difference Vegetation Index, Green NDVI)

$\mathrm{r}_{800}$ - radiação na banda $800 \mathrm{~nm}$

$\mathrm{r}_{550}$ - radiação na banda $550 \mathrm{~nm}$

A análise estatística dos dados se constituiu de uma análise exploratória seguida de modelagem. Na elaboração dos modelos empregaram-se três métodos de seleção automática de variáveis: stepwise forward, stepwise backward e melhor subconjunto de variáveis. O coeficiente de determinação múltipla ajustado ( $\mathrm{R}^{2}$ ajustado) foi utilizado para mostrar os melhores modelos. Utilizou-se a média entre os dados dos radiômetros 2 e 3 para a direção NS e, para a direção LO, somente os dados do radiômetro 1 , visto que o radiômetro 5 apresentou reflectâncias marcadamente menores quando comparadas aos outros, o que não era esperado, visto que todas as plantas estavam no mesmo estádio vegetativo e receberam a mesma quantidade de nutrientes. Como já comentado, este fato deve ter ocorrido por mau posicionamento do radiômetro sobre a planta.

Para elaborar os modelos da reflectância espectral do milho ( $r$ ) e do índice de vegetação verde normalizado (IVVDN) selecionaram-se as variáveis: ângulo zenital ( $\psi$, graus), hora do dia ( $\mathrm{t}$, hora) e direção de semeadura (dir), variável binária (0 para a direção LO e 1 para a direção NS). Essas variáveis foram selecionadas por se correlacionarem com a posição de Sol e o grau de iluminação da cultura, fatores influentes na reflectância (Davis, 1957; Jackson et al.; 1979; e Tumbo et al., 2000). Visando reduzir a esperada multicolinearidade pelo uso de modelos polinomiais, as variáveis quantitativas independentes foram transformadas para ângulo zenital centrado $\left(\psi_{\mathrm{C}}\right)$ e hora do dia centrada $\left(\mathrm{t}_{\mathrm{C}}\right)$, através de

$$
\begin{aligned}
& \psi_{\mathrm{C}}=\psi-45 \\
& \mathrm{t}_{\mathrm{C}}=\mathrm{t}-13
\end{aligned}
$$

em que as constantes de centralização foram escolhidas para propiciar uma simetria dos dados, isto é, 45 , como a metade do máximo ângulo zenital possível, e 13 como a hora aproximada do meio solar. Após uma análise exploratória dos dados optouse por ajustar os dados ao seguinte modelo

$$
\begin{gathered}
\mathrm{Y}=\mathrm{a}+\mathrm{bt}_{\mathrm{C}}+\mathrm{ct}_{\mathrm{C}}{ }^{2}+\mathrm{d} \psi_{\mathrm{C}}+\mathrm{e}_{\mathrm{C}}{ }^{2}+\mathrm{ft}_{\mathrm{C}} \psi_{\mathrm{C}}+ \\
\mathrm{g} \operatorname{dir}+\mathrm{h} \operatorname{dir} \mathrm{t}_{\mathrm{C}}+\mathrm{i} \operatorname{dir} \mathrm{t}_{\mathrm{C}}{ }^{2}+\varepsilon
\end{gathered}
$$

em que:

y - variável resposta $\left(\mathrm{r}_{550}\right.$ ou IVVDN)

a, b, c, d, e, f, g, h, i - parâmetros do modelo a serem estimados

$\varepsilon \quad$ - erro aleatório

\section{RESULTADOS E DISCUSSÃO}

A Figura 1 apresenta a dispersão dos dados da reflectância na banda $550 \mathrm{~nm}$ obtida com os quatro radiômetros para os três dias, em função do tempo. Verifica-se que, com exceção do radiômetro 5, os outros três radiômetros apresen-taram resultados similares no período da tarde. Comparando-se os quatro radiômetros constata-se que, diferentemente dos radiômetros 1 e 5 (LO), as reflectâncias associadas aos radiômetros 2 e 3 (NS) não apresentaram visualmente diferenças entre si. Os radiômetros posicionados sobre milho semeado na direção LO mostraram reflectâncias médias maiores e menos dependentes da hora do dia que os radiômetros da direção NS, confirmando o encontrado por Jackson et al. (1979) de que a direção de semeadura do milho influencia na reflectância apresentada pelas plantas. A influência da hora do dia na reflectância foi maior no milho semeado na direção NS, pelo fato de que a irradiação atingiu diretamente as folhas pela manhã 
e principalmente elas, mas com o decorrer do dia a parcela dessa irradiação que atinge o solo foi aumentando, alcançando o seu máximo perto do meio dia. A influência da hora do dia na reflectância foi menor no milho semeado na direção LO, visto que a irradiação atinge igualmente solo e planta, praticamente todo o dia. Ressalte-se que é esperada uma diminuição da influência da direção de semeadura a medida em que a cultura cresce e maior parte do solo é coberta pelo dossel.

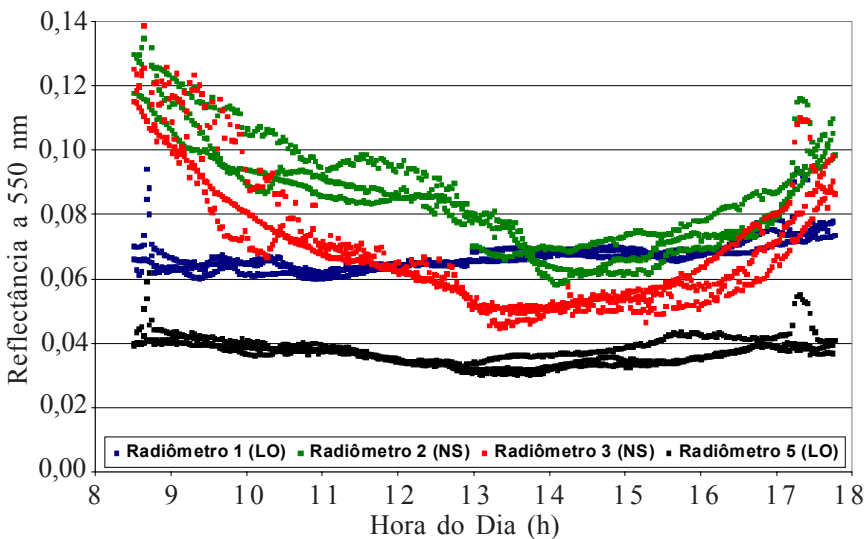

Figura 1. Reflectância na banda $550 \mathrm{~nm}$ no período de 03 a 05/09/2002, para os radiômetros 1 e 5 sobre milho semeado na direção Leste-Oeste (LO) e para os radiômetros 2 e 3 sobre milho semeado na direção Norte-Sul (NS), em função do tempo (hora do dia)

O comportamento da dispersão dos dados da reflectância na banda $550 \mathrm{~nm}$ para o período de 03 a $05 / 09 / 2002$, para os quatro radiômetros e em função do ângulo zenital está apresentado na Figura 2. A reflectância aumentou com o ângulo zenital, alcançando o máximo no início e no fim do dia. Além disto, a reflectância do milho semeado na direção LO se manteve mais constante com o ângulo zenital que o milho semeado na direção NS.

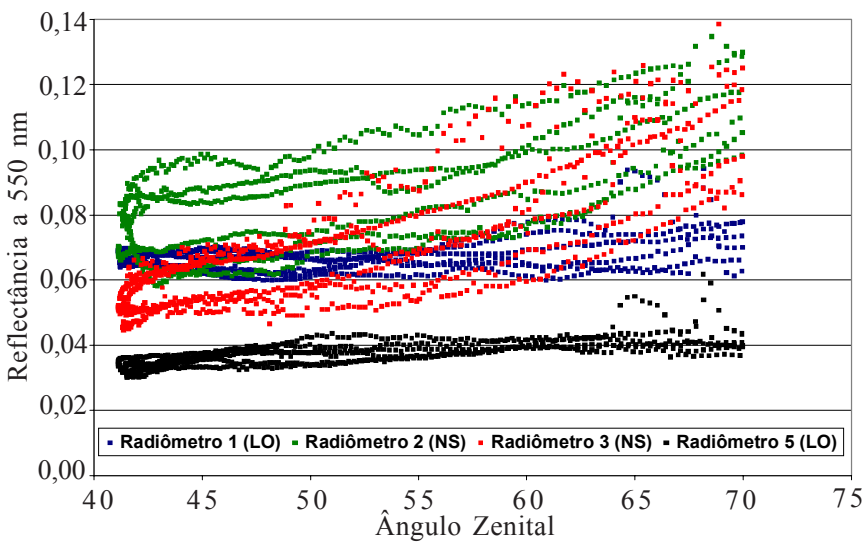

Figura 2. Reflectância na banda $550 \mathrm{~nm}$ no período de 03 a 05/09/2002, para os radiômetros 1 e 5 sobre milho semeado na direção Leste-Oeste (LO) e para os radiômetros 2 e 3 sobre milho semeado na direção Norte-Sul (NS), em função do ângulo zenital

$\mathrm{Na}$ Tabela 1 tem-se a análise estatística descritiva dos dados de reflectância para os dias 03, 04 e 05/09/2002. Como já visto, o milho sob o radiômetro 5 apresenta, em todos os dias, menores reflectâncias quando comparadas com as dos outros radiômetros, o que não era esperado, visto que todas as plantas estavam no mesmo estádio vegetativo e receberam a mesma quantidade de nutrientes. Verifica-se também que os resultados associados aos radiômetros 1 e 5 (direção LO) apresentaram menor variabilidade, visto que mostraram os menores coeficientes de variação $(\mathrm{CV})$. Percebe-se também que a direção de semeadura influenciou na reflectância, sendo que as plantas semeadas na direção NS indicaram, em média, valores maiores de reflectância (de 7,3 a 10,1\%), quando comparadas com as semeadas na direção LO (de 3,7 a 6,9\%); isto evidencia a interação entre a geometria da radiação e a arquitetura das plantas.

Tabela 1. Estatística descritiva para os dados de reflectância na banda $550 \mathrm{~nm}$ dos dias 03, 04 e 05/09/2002, respectivamente

\begin{tabular}{lcccc}
\hline \multicolumn{1}{c}{ Data } & $\begin{array}{c}\text { Rad. 1 } \\
\text { (dir. LO) }\end{array}$ & $\begin{array}{c}\text { Rad. 2 } \\
\text { (dir. NS) }\end{array}$ & $\begin{array}{c}\text { Rad. 3 } \\
\text { (dir. NS) }\end{array}$ & $\begin{array}{c}\text { Rad. 5 } \\
\text { (dir. LO) }\end{array}$ \\
\hline 03/09/2002 & & & & \\
Média & 0,0674 & 0,0877 & 0,0725 & 0,0392 \\
Desvio padrão & 0,0059 & 0,0154 & 0,0190 & 0,0036 \\
Mínimo & 0,0599 & 0,0661 & 0,0497 & 0,0325 \\
Máximo & 0,0939 & 0,1460 & 0,1198 & 0,0550 \\
Quartil 1 & 0,0630 & 0,0740 & 0,0570 & 0,0360 \\
Mediana & 0,0670 & 0,0850 & 0,0670 & 0,0390 \\
Quartil 3 & 0,0690 & 0,0950 & 0,0840 & 0,0410 \\
C.V. & $8,79 \%$ & $17,61 \%$ & $26,14 \%$ & $9,22 \%$ \\
\hline 04/09/2002 & & & & \\
Média & 0,0697 & 0,0977 & 0,0825 & 0,0370 \\
Desvio padrão & 0,0113 & 0,0308 & 0,0397 & 0,0051 \\
Mínimo & 0,0617 & 0,0612 & 0,0446 & 0,0316 \\
Máximo & 0,1679 & 0,2864 & 0,3256 & 0,0789 \\
Quartil 1 & 0,0650 & 0,0740 & 0,0548 & 0,0340 \\
Mediana & 0,0670 & 0,0960 & 0,0710 & 0,0370 \\
Quartil 3 & 0,0700 & 0,1130 & 0,1000 & 0,0390 \\
C.V. & $16,15 \%$ & $31,50 \%$ & $48,17 \%$ & $13,72 \%$ \\
\hline 05/09/2002 & & & & \\
Média & 0,0691 & 0,1007 & 0,0840 & 0,0382 \\
Desvio padrão & 0,0122 & 0,0397 & 0,0408 & 0,0067 \\
Mínimo & 0,0614 & 0,0583 & 0,0450 & 0,0301 \\
Máximo & 0,1640 & 0,3060 & 0,3077 & 0,0780 \\
Quartil 1 & 0,0650 & 0,0740 & 0,0570 & 0,0340 \\
Mediana & 0,0670 & 0,0885 & 0,0700 & 0,0380 \\
Quartil 3 & 0,0690 & 0,1153 & 0,1050 & 0,0400 \\
C.V. & $17,69 \%$ & $39,40 \%$ & $48,55 \%$ & $17,51 \%$ \\
\hline
\end{tabular}

C.V. - Coeficiente de Variação

Outra forma de se avaliar a radiação refletida por uma cultura é a utilização de índices de vegetação. A Figura 3 apresenta a dispersão dos dados do índice verde de vegetação da diferença normalizada (IVVDN) referente aos quatro radiômetros para os três dias, em função do tempo. Comparando-se as Figuras 1 e 3, observa-se que o IVVDN apresentou menor dependência com a hora do dia que a reflectância na banda $550 \mathrm{~nm}$. Este fato contraria Jackson et al. (1979) que encontraram acentuada influência da hora do dia em índices que usam a relação de infravermelho-próximo/verde, provavelmente por eles terem trabalhado com cultura do trigo. Com exceção do índice IVVDN 5 (radiômetro 5), os índices de vegetação da direção LO e NS apresentaram-se mais agrupados que as respectivas reflectâncias. Por outro lado, os radiômetros 2 e 3 (direção NS), 
assim como para a reflectância a $550 \mathrm{~nm}$, mostraram também maiores valores de IVVDN quando comparados com os radiômetros 1 e 5 (direção LO). Os baixos valores de índice de vegetação observados pelo radiômetro 5 reiteram a suspeita de que houve problemas de posicionamento deste radiômetro sobre a planta.

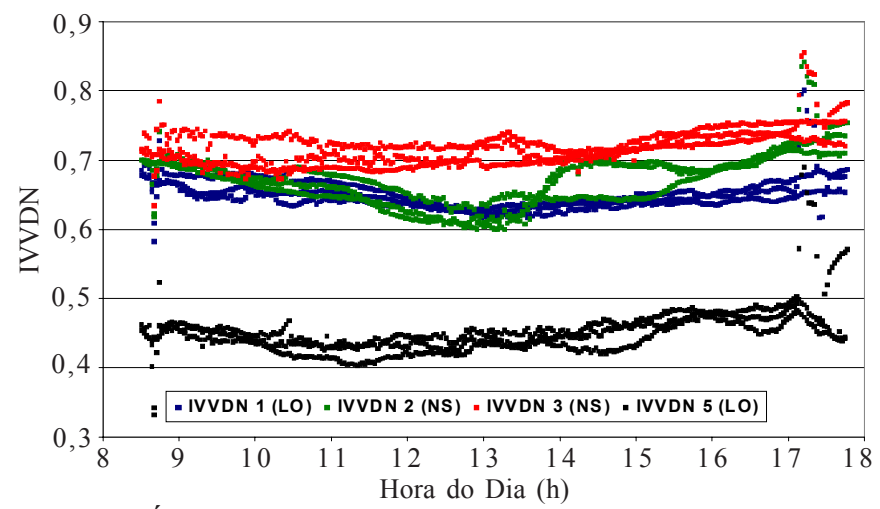

Figura 3. Índice verde de vegetação da diferença normalizada

IVVDN no período de 03 à 05/09/2002, para os radiômetros 1 e 5 (direção LO) e 2 e 3 (direção NS), em função do tempo (hora do dia)

A Tabela 2 apresenta a análise estatística descritiva para os valores do índice verde de vegetação da diferença normalizada. Observa-se que os radiômetros posicionados sobre milho semeado na direção NS apresentaram maiores valores de índice de

Tabela 2. Estatística descritiva para o índice verde de vegetação da diferença normalizada (IVVDN) para os dias 3, 4 e 5/09/2002, respectivamente

\begin{tabular}{|c|c|c|c|c|}
\hline Data & IVVDN 1 & IVVDN 2 & IVVDN 3 & IVVDN 5 \\
\hline \multicolumn{5}{|l|}{$3 / 9 / 2002$} \\
\hline Média & 0,6508 & 0,6685 & 0,7116 & 0,4624 \\
\hline Desvio padrão & 0,0243 & 0,0417 & 0,0294 & 0,0456 \\
\hline Mínimo & 0,6169 & 0,5543 & 0,6793 & 0,4243 \\
\hline Máximo & 0,8012 & 0,8418 & 0,8554 & 0,6904 \\
\hline Quartil 1 & 0,6372 & 0,6447 & 0,6918 & 0,4358 \\
\hline Mediana & 0,6427 & 0,6546 & 0,7027 & 0,4461 \\
\hline Quartil 3 & 0,6556 & 0,6933 & 0,7217 & 0,4658 \\
\hline C.V. & $3,74 \%$ & $6,24 \%$ & $4,14 \%$ & $9,85 \%$ \\
\hline \multicolumn{5}{|l|}{ 4/9/2002 } \\
\hline Média & 0,6515 & 0,6787 & 0,7179 & 0,4591 \\
\hline Desvio padrão & 0,0297 & 0,0459 & 0,0287 & 0,0486 \\
\hline Mínimo & 0,4473 & 0,4836 & 0,5425 & 0,2540 \\
\hline Máximo & 0,7998 & 0,8473 & 0,8470 & 0,6792 \\
\hline Quartil 1 & 0,6350 & 0,6577 & 0,7000 & 0,4247 \\
\hline Mediana & 0,6508 & 0,6877 & 0,7165 & 0,4480 \\
\hline Quartil 3 & 0,6610 & 0,7035 & 0,7356 & 0,4829 \\
\hline C.V. & $4,56 \%$ & $6,76 \%$ & $4,00 \%$ & $10,59 \%$ \\
\hline \multicolumn{5}{|l|}{$5 / 9 / 2002$} \\
\hline Média & 0,6714 & 0,6965 & 0,7445 & 0,4757 \\
\hline Desvio padrão & 0,0406 & 0,0476 & 0,0352 & 0,0609 \\
\hline Mínimo & 0,5311 & 0,6073 & 0,6252 & 0,3061 \\
\hline Máximo & 0,9095 & 0,9341 & 0,9369 & 0,8457 \\
\hline Quartil 1 & 0,6450 & 0,6708 & 0,7225 & 0,4463 \\
\hline Mediana & 0,6693 & 0,6936 & 0,7362 & 0,4557 \\
\hline Quartil 3 & 0,6836 & 0,7163 & 0,7548 & 0,4802 \\
\hline C.V. & $6,04 \%$ & $6,84 \%$ & $4,73 \%$ & $12,79 \%$ \\
\hline
\end{tabular}

C.V. - Coeficiente de Variação vegetação e, ainda que as variabilidades dos IVVDN foram menores que as da reflectância $r_{550}$, visto que os coeficientes de variação também foram muito menores. Percebe-se que a direção de semeadura influenciou bem menos no IVVDN que na reflectância.

Desenvolveram-se modelos através do método de mínimos quadrados para descrever a dependência das variáveis respostas $r_{550}$ e IVVDN em relação às variáveis ângulo zenital centrado $\left(\psi_{\mathrm{C}}\right)$, hora do dia centrada $\left(\mathrm{t}_{\mathrm{C}}\right)$ e direção de semeadura (dir). A explicação da variabilidade das variáveis dependentes através dos modelos, foi maior que $86 \%$, visto que o $\mathrm{R}^{2}$ encontrado foi 0,866 para o índice de vegetação IVVDN e de 0,901 para a reflectância $\mathrm{r}_{550}$ (Tabela 3). Ressalte-se que a inclusão da variável binária dir ( 0 para a direção LO, 1 para a direção NS) possibilitou a construção de um único modelo para ambas as direções, para cada variável resposta.

Tabela 3. Coeficientes de regressão para a reflectância do milho na banda de $550 \mathrm{~nm}\left(\mathrm{r}_{550}\right)$ e para o índice verde de vegetação da diferença normalizada (IVVDN) em função da hora do dia centrada $\left(\mathrm{t}_{\mathrm{C}}\right)$, do ângulo zenital centrado $\left(\psi_{\mathrm{C}}\right)$ e da direção de semeadura (dir)*

\begin{tabular}{ccc}
\hline \multirow{2}{*}{ Parâmetros do Modelo } & \multicolumn{2}{c}{$\mathrm{R}^{2}$} \\
\cline { 2 - 3 } & $\mathrm{r}_{550}$ & IVVDN \\
\hline Intercept & 0,05096 & 0,7537 \\
$\mathrm{t}_{\mathrm{C}}$ & $-0,001195$ & 0,01149 \\
$\mathrm{t}_{\mathrm{C}}$ & 0,006050 & $-0,04706$ \\
$\psi_{\mathrm{C}}$ & $-0,004282$ & 0,03378 \\
$\psi_{\mathrm{C}}{ }^{2}$ & 0,00005177 & 0,0001246 \\
$\mathrm{t}_{\mathrm{C}}{ }^{2} \psi_{\mathrm{C}}$ & $-0,001500$ & 0,04027 \\
$\operatorname{dir}$ & $-0,005300$ & 0,005159 \\
$\operatorname{dir} * \mathrm{t}_{\mathrm{C}}$ & 0,001739 & 0,0006504 \\
$\operatorname{dir} * \mathrm{t}_{\mathrm{C}}{ }^{2}$ & 0,901 & 0,866 \\
$\mathrm{R}^{2}$ &
\end{tabular}

*Todos os estimadores dos coficientes de regressão foram significativos em nível de $0,1 \%$ de probabilidade pelo teste $\mathrm{F}$. A dose de $\mathrm{N}$ foi de $160 \mathrm{~kg} \mathrm{ha}^{-1}$. O estádio vegetativo do milho durante o período de teste (de 03/09 a 05/09/2002) era V7

A Figura 4 apresenta os intervalos de predição para a variável reflectância a nível de $95 \%$ de confiança. Os intervalos de predição, como era de se esperar, abrangem a maioria dos valores medidos. Vê-se, também, que os intervalos das direções NS e LO se sobrepõem entre 11:00 e 18:00 h. O intervalo da direção NS é muito mais largo que o LO, devido principalmente a pontos discrepantes.

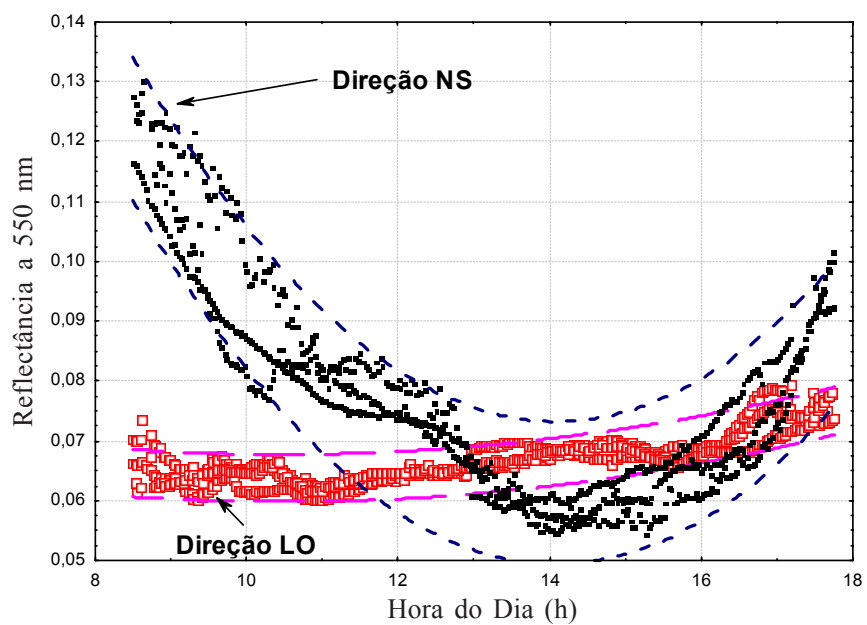

Figura 4. Intervalos de predição a nível de $95 \%$ de confiança para as reflectâncias na banda de $550 \mathrm{~nm}\left(\mathrm{r}_{550}\right)$ calculadas para direção Norte-Sul (NS) e na direção Leste-Oeste (LO) 
Na Figura 5 observam-se os intervalos de predição a nível de $95 \%$ de confiança para o índice verde de vegetação da diferença normalizada. Os intervalos de predição são muito mais próximos que os encontrados para a variável $r_{550}$. Enquanto para a variável $r_{550}$ a direção de semeadura influencia na interação entre a variável dependente $\mathrm{r}_{550}$ e a hora do dia, para a variável IVVDN, a direção de semeadura contribui principalmente com um valor aditivo à variável dependente $r_{550}$.

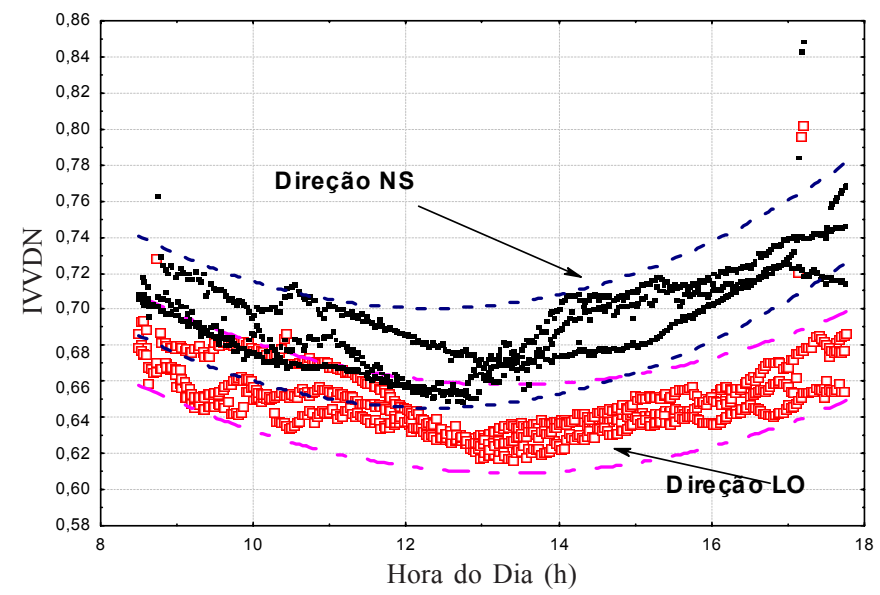

Figura 5. Intervalos de predição a nível de $95 \%$ de confiança para os índices de vegetação da diferença normalizada (IVVDN) calculados para a direção Norte-Sul (NS) e na direção LesteOeste (LO)

\section{CONCLUSÕES}

1. O direcionamento da semeadura do milho em relação à trajetória do Sol, influenciou a reflectância $r_{550}$ e o índice de vegetação IVVDN.

2. O milho semeado na direção Leste-Oeste apresentou valores de reflectância $r_{550}$ e índice de vegetação IVVDN menores e menos dependentes da hora do dia que o milho semeado na direção Norte-Sul.

3. A direção de semeadura influenciou de forma diferente as variáveis analisadas. Na variável $r_{550}$ a direção de semeadura resultou em uma interação significativa entre a variável dependente $\mathrm{r}_{550}$ e a hora do dia. Para a variável IVVDN a direção de semeadura contribui principalmente com um valor aditivo à variável dependente IVVDN.

4. O índice verde de vegetação da diferença normalizada mostrou-se mais apropriado para uso em sistemas de aplicação de fertilizantes a taxas variáveis em tempo real, utilizando-se técnicas de sensoreamento remoto por se mostrar menos sensível à direção de semeadura.

\section{AGRADECIMENTOS}

Os autores agradecem o apoio financeiro propiciado pela University of Missouri, Columbia-MO, EUA, e pelo Conselho Nacional de Desenvolvimento Científico e Tecnológico CNPq. Agradecem, também, o apoio técnico disponibilizado por Larry Mueller e Bettina Coggeshall, nos trabalhos de campo.

\section{LITERATURA CITADA}

Balastreire, L.A.; Elias, A.I.; Amaral, J.R. Agricultura de precisão: Mapeamento da produtividade da cultura de milho. Revista de Engenharia Rural, Piracicaba, v.8, p.97-111, 1997.

Blackmer, T.M.; Schepers, J.S.; Varvel, G.E. Light reflectance compared with other nitrogen stress measurement in corn leaves. Agronomy Journal, Madison, v.86. p.934-938, 1994.

Daughtry, C.S.T.; Walthall, C.L.; Kim, M.S.; Brown de Colstoun, E.; Mcmurtrey III, J.E. Estimating corn leaf chlorophyll concentration from leaf and canopy reflectance. Remote Sensing of Environment, New York, p.229-239, 2000.

Davis, P.A. Exploring the atmosphere's first mile. Lettau, H.H.; Davidson, B. (eds.) New York: Proceedings of the Great Plains turbulence field program, Symposium Publications Division, Pergamon Press, 1957. p.377-383.

Jackson, R.D.; Pinter, P.J.; Idso, S.B.; Reginato, R.J. Wheat spectral reflectance: Interactions between crop configuration, sun elevation, and azimuth angle. Applied Optics, v.18, n.3, p.730-33, 1979.

Souza, E.G.; Scharf, P.; Sudduth, K. How corn reflectance and vegetation indices are influenced by sun position and atmospheric conditions. In: 2002 Mid-Central ASAE Meeting. Proceedings.... St. Joseph: ASAE. 2002. ASAE Paper No. MC02-06

Tumbo, D.S.; Wagner, D.G.; Heinenmann, P.H. Real-world hyperspectral characteristics of corn plants under different chlorophyll levels. In: 2000 ASAE Annual International Meeting. Proceedings... Mineapolis: ASAE. 2000. ASAE Paper No. 001093

Wood, C.W.; Reeves, D.W.; Himelrick, D.G. Relationships between chlorophyll meter readings and leaf chlorophyll concentration, N status, and crop yield: A review. Proceedings.... New Zealand: Agronomy Society., 1993. p.1-9. 